\title{
INCIDENCE OF GESTATIONAL DIABETES MELLITUS AND ITS OUTCOMES IN A RURAL POPULATION
}

Alpana Singh, B. Uma

1. Assistant Professor. Department of Obstetrics \& Gynecology, Bhaskar Medical College, Hyderabad,

2. Professor \& HOD. Department of Obstetrics \& Gynecology, Bhaskar Medical College, Hyderabad,

\section{CORRESPONDING AUTHOR:}

Dr. Alpana Singh,

Assistant Professor,

Malla Reddy Medical College,

Hyderabad, Andhra Pradesh.

E-mail: dralpanasingh21@gmail.com

ABSTRACT: BACKGROUND: Gestational diabetes mellitus (GDM) is a disorder of carbohydrate metabolism with grave consequences for both the mother and child. Numerous methodologies for the diagnosis of GDM have been proposed. We used the Diabetes in pregnancy study group India (DIPSI) procedure to diagnose GDM. The objectives of this study are to find out the incidence of gestational diabetes mellitus in pregnant women and their pregnancy outcomes in a rural setting. MATERIALS AND METHODS: It is a hospital based prospective study performed on 400 pregnant women between 24 to 28 weeks of gestation over a period of one year. All were given a 75 gms oral glucose load, irrespective of their last meal, and venous plasma glucose was estimated after 2 hours. Cases with 2 hours plasma glucose value $\geq 140 \mathrm{mg} \%$ were diagnosed as GDM. All GDM patients were followed up and treated with medical nutrition therapy (MNT) and/or insulin therapy till delivery to know the maternal and foetal outcomes. RESULTS: The incidence of GDM was $5.7 \%$ using the DIPSI method. GDM was observed more frequently in age $\geq 25 y e a r s(34.8 \%)$, BMI $\geq 25(39.1 \%)$, past history of GDM (4.3\%), family history (13\%), history of previous pregnancy loss (8.7\%), and history of polyhydramnios (8.7\%). The foetal and maternal outcomes in GDM were: anencephaly (4.3\%), gestational hypertension (8.7\%), macrosomia $(13.0 \%)$ and preterm delivery (17.4\%). CONCLUSION: Women with GDM are at an increased risk for adverse obstetric and perinatal outcome. Screening the pregnant women for GDM and achieving euglycemia can prevent maternal and foetal complications. Hence, universal instead of selective screening should be mandatory. DIPSI procedure is a one step cost effective procedure for diagnosis and management of GDM.

KEYWORDS: gestational diabetes mellitus, DIPSI, medical nutrition therapy (MNT), insulin

INTRODUCTION: Gestational diabetes mellitus (GDM) is defined as any degree of carbohydrate intolerance with the first recognition or onset during pregnancy, irrespective of treatment with diet or insulin, with or without remission after the end of pregnancy [1]. The importance of GDM is that two generations (mother and child) are at risk of developing diabetes in future; predominantly type 2 diabetes mellitus [2]. GDM is associated with increased incidence of maternal hypertension, pre-eclampsia, obstetric intervention and risk of developing diabetes mellitus (DM) in later life [3]. Infants of diabetic mothers stand the risk of growth restriction, congenital malformations, respiratory distress, polycythemia, hypoglycemia, hypocalcaemia and hypomagnesaemia [4]. 
MATERIALS AND METHODS: This is a prospective study conducted on pregnant women attending the antenatal OPD in the department of obstetrics and gynaecology, Bhaskar Medical College and Hospital, Hyderabad over a period of one year from April 2011 to March 2012. Pregnant women between (24 to 28) ${ }^{[\mathrm{H} 1]}$ weeks of gestation were included in the study. Cases having pregestational diabetes, and major chronic illnesses were excluded. A standard questionnaire was used and details pertaining to their anthropometric, medical, family and obstetric history were collected.

After obtaining an informed consent, subjects were given $75 \mathrm{~g}$ of glucose irrespective of their last meal. Venous plasma glucose was estimated after 2 hours, and cases with 2 hours plasma glucose value $\geq 140 \mathrm{mg} / \mathrm{dl}$ were diagnosed as having GDM. All GDM patients were followed up and treated with medical nutrition therapy (MTN) and/or insulin therapy till delivery. Data was evaluated and the (incidence)[H2], maternal and fetal outcomes of GDM studied.

Statistical testing was conducted with the statistical package for the social science system version SPSS 17.0.Continuous variables are presented as mean \pm SD, and categorical variables are presented as absolute numbers and percentage. The comparison of continuous variables between the groups was performed using Student's t test. Nominal categorical data between the groups were compared using Chi-squared test or Fisher's exact test as appropriate. The alpha level for all analyses was set as $p$ value less than 0.05 .

RESULTS: The mean maternal age of pregnant patients was 22.20 (S.D 2.96) years and mean BMI was 21.80 (S.D 2.39). Out of 400 cases, 23 (5.7\%) were diagnosed as having GDM using the DIPSI method.

\section{Distribution of cases according to gravida and occurrence of GDM (Table 1):}

Table 1: Distribution of cases according to gravida

\begin{tabular}{|l|l|l|l|l|}
\hline Gravida & $\begin{array}{l}\text { No of cases } \\
(\mathrm{n}=400)\end{array}$ & $\begin{array}{l}\text { Non GDM } \\
(\mathrm{n}=377)\end{array}$ & $\begin{array}{l}\text { GDM } \\
(\mathrm{n}=23)\end{array}$ & P value \\
\hline G1 & $200(50 \%)$ & $186(49.3 \%)$ & $14(60.9 \%)$ & 0.283 \\
\hline G2 & $154(38.5 \%)$ & $147(39 \%)$ & $7(30.4 \%)$ & 0.413 \\
\hline$\geq$ G3 & $46(11.5 \%)$ & $44(11.7 \%)$ & $2(8.7 \%)$ & 1.000 \\
\hline
\end{tabular}

In our study most of the cases were primigravida (50\%), however there was no statistically significant association between gravida and GDM.

\section{Distribution of cases according to age and occurrence of GDM (Table 2):}

Most of the pregnancies were in the age group of 20 to 25 years (76\%). There was a significant correlation between GDM and age $>30$ years

Table 2: Distribution of cases according to age and occurrence of GDM:

\begin{tabular}{|l|l|l|l|l|}
\hline Age group (years) & No of cases & NonGDM (n=377) & GDM (n=23) & P value \\
\hline$<20$ & $53(13.3 \%)$ & $53(14.1 \%)$ & $0(0 \%)$ & 0.053 \\
\hline $20-25$ & $304(76 \%)$ & $287(76.1 \%)$ & $17(73.9 \%)$ & 0.809 \\
\hline $26-30$ & $33(8.3 \%)$ & $30(8.0 \%)$ & $3(13 \%)$ & 0.389 \\
\hline$>30$ & $10(2.5 \%)$ & $7(1.9 \%)$ & $3(13 \%)$ & 0.0008 \\
\hline
\end{tabular}




\section{Prevalence of risk factors in study population (Table 3):}

Out of 23 diagnosed cases of GDM, 16 cases were having one or more risk factors, while 7 cases were without any risk factors. Total number of cases with high risk factors was 121(39.2\%).

Table 3: Prevalence of risk factors in study population

\begin{tabular}{|l|l|l|l|l|}
\hline Risk factors & No of cases & Non GDM & GDM & P VALUE \\
\hline Age $\geq 25$ years & $54(13.5 \%)$ & $46(12.2 \%)$ & $8(34.8 \%)$ & 0.002 \\
\hline BMI $\geq 25 \mathrm{Kg} / \mathrm{m} 2$ & $29(7.3 \%)$ & $20(5.3 \%)$ & $9(39.1 \%)$ & $<0.001$ \\
\hline Family history & $12(3.0 \%)$ & $9(2.4 \%)$ & $3(13 \%)$ & 0.026 \\
\hline Past H/O GDM & $2(0.5 \%)$ & $1(0.3 \%)$ & $1(4.3 \%)$ & 0.112 \\
\hline H/O pregnancy loss & $39(9.8 \%)$ & $37(9.8 \%)$ & $2(8.7 \%)$ & 1.000 \\
\hline Polyhydramnios & $10(2.5 \%)$ & $8(2.12 \%)$ & $2(8.7 \%)$ & 0.050 \\
\hline
\end{tabular}

\section{Pregnancy outcomes in GDM cases (Table 4):}

2 cases were lost to follow up. Most of the patients were managed with medical nutrition therapy and only $3(13 \%)$ cases needed Insulin.

Table 4: Pregnancy outcomes in GDM cases:

\begin{tabular}{|l|l|}
\hline Congenital anomaly & $1(4.3 \%)$ \\
\hline Preterm delivery & $4(17.4 \%)$ \\
\hline Gestational hypertension & $2(8.7 \%)$ \\
\hline Requirement of insulin & $3(13.0 \%)$ \\
\hline Vaginal delivery & $16(69.5 \%)$ \\
\hline Caesarean section & $5(21.7 \%)$ \\
\hline Macrosomia ( birth wt > 3.45Kg) & $3(13.0 \%)$ \\
\hline
\end{tabular}

DISCUSSION: Studies conducted in different population with different methodologies consistently reported an increase in GDM in all race/ethnic groups and our study also endorses the same, suggesting that there is an increase in GDM prevalence [5]. In the Indian context, women have eleven fold increased risk of developing glucose intolerance during pregnancy compared with Caucasian women [6]. This implies that universal screening and care of GDM is of paramount public health priority rather than risk factor screening [7].

To standardize the diagnosis of GDM, World Health Organization (WHO) has proposed 2 hours 75gms OGTT, with a threshold of plasma glucose $>140 \mathrm{mg} / \mathrm{dl}$ at 160 mins similar to impaired glucose tolerance outside pregnancy [8]. Diabetes in pregnancy study group India (DIPSI) procedure of diagnosis is a modified version of the WHO criteria. The WHO procedure requires the women to be in fasting, whereas DIPSI procedure is performed irrespective of the last meal timing [9]. The rationale is that, after a meal, a normal glucose tolerant woman would be able to maintain euglycemia despite glucose challenge due to brisk and adequate insulin response. Whereas, in a woman with impaired insulin secretion, the glycemic excursion exaggerates further with glucose challenge [10]. This cascading effect is advantageous as this would not result in false positive diagnosis of GDM [10]. DIPSI procedure is a one step procedure which screens as well as and diagnoses GDM. It is simple, economical and feasible. 
In our study the total incidence of GDM was 5.7\%, more cases being in high risk group $(13.2 \%)$ than in low risk group (2.8\%). Though GDM occurrence was more in high risk group, it was not absent in low risk group. This further signifies the need of universal screening in pregnant women for GDM $[7,11]$.

Age $\geq 25$, BMI $\geq 25$ and history of GDM in previous pregnancy were the most significant risk factors observed in our study to be associated with GDM.

Multiple studies support the idea that GDM appears more frequently in pregnancy after the age 25 because of age-related metabolic changes like increased BMI, hypertension and dyslipidemia and it is rare before age 20 . In our study $34.8 \%$ of GDM cases were in age group $\geq 25$ years. A similar study from South India done by Seshiah V. et al showed age $\geq 25$ years as a risk factor for GDM [12].

Obesity is a significant risk factor for GDM, causing hormonal imbalance of carbohydrate regulation mechanism and insulin sensitivity. Our study showed that 39.1\% GDM cases were having BMI $\geq 25 \mathrm{~kg} / \mathrm{m}^{2}$, which is in accordance with a study done by Hadaegh F. et al showing BMI $\geq 25 \mathrm{~kg} / \mathrm{m}^{2}$ more prevalent in GDM subjects [13].

In the present study $13 \%$ cases with history of GDM in previous pregnancy develop GDM. A study conducted by Catherine Kim MD et al also concluded that recurrence of GDM varies between $30-80 \%$ depending on race, ethnicity, maternal age, and BMI [14].

Our study revealed $4.3 \%$ incidence of congenital anomaly, $8.7 \%$ incidence of gestational hypertension and $17.4 \%$ incidence of preterm labor in GDM cases. Many studies have suggested that risk of congenital malformations are more in pregnant women with pre-existing but undetected type 2 diabetes mellitus. A study done on 2359 pregnant women with diabetes in England, Wales and Northern Ireland showed 4 fold increase in congenital anomaly than general population [15]. A prospective study on 1310 women in Iran showed that GDM women had higher rate of hypertension, polyhydramnios and caesarean section [16]. A similar study done by Kvetny $\mathrm{J}$ Poulsen HF on incidence of gestational hypertension in gestational diabetes mellitus showed that gestational hypertension appeared with a higher frequency in women with GDM (28\%) than in women with normal OGTT (10\%) [17].

In our study $69.5 \%$ of GDM cases were delivered vaginally while $21.7 \%$ cases required a caesarean section, which is in agreement with a similar study from Saudi Arabia showing $74.6 \%$ spontaneous vertex deliveries, and $21.6 \%$ lower segment cesarean section in 685 women with gestational diabetes mellitus [18].

In our study macrosomia i.e. babies with birth weight $\geq 3.45 \mathrm{~kg}$ ( $90^{\text {th }}$ percentile) was observed in 13\% newborns of GDM mothers. A study conducted by Vedavathi KJ et al in 2010 on Influence of Gestational Diabetes Mellitus on Fetal growth parameters concluded that despite the attempts for good glycemic control there is a risk of macrosomia in GDM [19]. While a similar study done by Balaji V. et al in 2011 ,showed the equal incidence of macrosomia in treated GDM women and normal glucose tolerant (NGT) women and concluded that intervention helped in maintaining the pregnancy outcome in GDM women equivalent to that of NGT women [20].

\section{REFERENCES:}

1. Metzger BE, Coustan DR. Summary and recommendations of the Fourth International Workshop Conference on Gestational Diabetes Mellitus: The Organizing Committee. Diabetes Care 1998; 21 Suppl 2; B 161-7. 
2. Dornhost A, Rossi M. Risk and prevention of Type 2 Diabetes in women with gestational diabetes. Diabetes Care 1998; 21 (Suppl 2):B43-9.

3. Davey RX, Hamblin PS. Selective versus universal screening for gestational diabetes mellitus: An evaluation of predictive risk factors. Med J Aust. 2001;174:118-21.

4. Opara PI, Jaja T, Onubogu UC. Morbidity and mortality amongst infants of diabetic mothers admitted into a special care baby unit in Port Harcourt, Nigeria. Ital J Pediatr. 2010; 36:77.

5. Ferrara A. Increasing prevalence of Gestational Diabetes Mellitus - A Public Health Perspective. Diabetes Care 2007; 30 (Suppl 2):S141-6.

6. Dornhost A,Paterson CM et al . High prevalence of GDM in women from ethinic minority groups. Diabetic Med 1992;9:820-822.

7. Shamsuddin K, Mahdy ZA, Siti Rafiaah I, Jamil MA, Rahimah MD. Risk factor screening for abnormal glucose tolerance in pregnancy. Int J Gynaecol Obstet 2001; 75:27-32.

8. Alberti KG, Zimmett PZ. Definition, diagnosis and classification of diabetes mellitus and its complications, Part 1: diagnosis and classification of diabetes mellitus provisional report of a WHO consultation. Diabet Med 1998; 15:539-53.

9. Anjalakshi C, Balaji V, Balaji MS, Ashalata S, Suganthi S, Arthi T, et al. A Single test procedure to diagnose gestational diabetes mellitus. Acta Diabetol 2009; 46:51-4.

10. Seshiah V, Sahay BK, Das AK, Shah S, Banerjee S, Rao PV, et al. Gestational Diabetes Mellitus - Indian Guidelines. J Indian Med Assoc 2009; 107:799-802, 804-6.

11. Das V, Kamra S, Mishra A. Screening for gestational diabetes and maternal and fetal outcome. J Obstet Gynaecol India. 2004; 54:449-51.

12. Seshiah V, Balaji V, Balaji MS, Paneerselvam A, Arthi T, Thamizharasi M, et al. Prevalence of gestational diabetes mellitus in South India (Tamil Nadu) - a community based study. J Assoc Physicians India 2008; 56:329-33.

13. Hadaegh F, Tohidi M, Harati H,Kharandish M and Rahimi S. Prevalence of gestational diabetes mellitus in Southern Iran. Endocr Pract 2005; 11: 313-318

14. Catherine Kim, MD,MPH, Diana K, Berger, MD, MPH, Shadi Chamany MD, MPH. Recurrence of gestational diabetes mellitus. Diabetes Care May 2007 vol. 30 no. 5 13141319.

15. Mary C M Macintosh,Kate M Fleming, Jaron A Bailey,Pat Doyle, Jo Modder,et al . Perinatal mortality and congenital anomalies in babies of women with type 1 or type 2 diabetes in England, Wales, and Northern Ireland: population based study. BMJ 2006; 333:177.

16. Keshavarz M, Cheung NW, Babaee GR et al. Gestational diabetes in Iran: incidence, risk factors and pregnancy outcomes. Diabetes Res Clin Pract 2005;69:276-286

17. Kvetny J, Poulsen HF. Incidence of gestational hypertension in gestational diabetes mellitus. Arch Gynecol obstet 2003 Jan; 267(3) : 153-7.

18. Malak M. Al-Hakeem. Pregnancy outcome of getational diabetic mother : expérience in a tertiary centre.Journal of family and community medicine 2006 ;13 (2).

19. Vedavathi KJ , Swamy Rm , Kanavi Roop Shekharappa , Venkatesh G , Veerananna HB Influence of Gestational Diabetes Mellitus on Fetal growth parameters Int J Biol Med Res. 2011; 2(3): 832-834.

20. Balaji V, Madhuri Balaji, Anjalakhi C, Cynthia A, Arati T, Seshiah V. Diagnosis of gestational diabetes mellitus in Asian-Indian women. Indian J Endocrino Metab 2011 ; 15(3); 187. 